\title{
From the Scalpel to the Water
}

\author{
Neşterden Suya
}

\author{
(D) Gianna Pace \\ ULSS 3 Serenissima, Clinic of Urology, Venice, Italy
}

\section{To the Editor,}

In the twentieth century, the surgical treatment of benign prostatic hyperplasia (BPH) is changing, hand to hand, with currently available technologies that are reshaping surgical procedures, evolving from open to minimally invasive approaches.

Men with clinically significant lower urinary tract symptoms (LUTS) due to BPH can be treated with drugs or surgically. Surgical intervention is an appropriate treatment for patients with moderate-to-severe LUTS, with acute urinary retention or other BPH-related complications.

For many years, transurethral resection of the prostate (TURP) has been considered the gold standard for surgical treatment of $\mathrm{BPH}$; nowadays Holmium laser enucleation of the prostate is challenging the role of traditional TURP. In 1999, TURP represented the $81 \%$ of surgical treatment for BPH versus $39 \%$ of 2005 (1).

The laser treatments have been developed in the last 15 years; laser resections can be performed using different kinds of energy: coagulative, cutting and vaporizing laser (2). It is safe with good haemostatic properties, able to treat bladder calculi at the same time and suitable for prostates of different volumes, of choice in the increasing number of patients on antiplatelet therapy.

The first laparoscopic simple prostatectomy was described in 2002 (3). In 2008, the first single-port simple laparoscopic prostatectomy was performed (4). In the recent years, laparoscopy has shown significant technological improvements, including introduction of $4 \mathrm{~K}$ Ultra HD video equipment, 3D HD video systems, miniaturized instruments with 7 degrees of freedom, and ergonomic platforms.
Not the least, also robot-assisted simple prostatectomy has been described with a 3-arm da Vinci Surgical System. Robotic surgery allows robotic arms to replicate the hand movements of the surgeon with greater precision with filtering out any tremor in the surgeon's hands while providing enhanced visualization in high definition 3 dimensional images and improvement in human performance $(5,6)$.

We are waiting for smaller robotic platforms with better maneuverability, providing force feedback and eye tracking capabilities to move the scope inside the patient according to the surgeons' eye movements.

Recently, a new robotic system, used in endourology, is under investigation: the AquaBeam ${ }^{\circledR}$-system for robot-assisted aquablation of the prostate. By using the power of water, pulsating near the speed of sound, the robot removes the prostatic tissue automatically. It is for the first time a surgical approach allows to eliminate the need for one surgical assistant!

We are witnesses of a revolution not only in the surgical approach to the patient but also of the environment where surgical interventions take place; hybrid operating rooms offer new visualization technologies to provide high-definition, 3-dimensional, real-time images guidance and to perform combined open, minimally invasive and image-guided procedures in the same theatre.

We are moving towards minimally invasive surgery with a switch from direct, hands-on surgical approaches to indirect, "hands-off" approaches as well as towards hybrid operating rooms which allow robotic surgery and telesurgery.

At the beginning, the growing interest in commercial spaceflight and the need of defense departments to have a trauma Pod that

Correspondence: Gianna Pace MD, ULSS 3 Serenissima, Clinic of Urology, Venice, Italy E-mail: giannapace@gmail.com ORCID-ID: orcid.org/0000-0003-3260-7440

Received: 24.09.2019 Accepted: 26.09.2019

Cite this article as: Pace G. From the Scalpel to the Water. J Urol Surg 2020;7(1):66-67.

${ }^{\circ}$ Copyright 2020 by the Association of Urological Surgery / Journal of Urological Surgery published by Galenos Publishing House. 
would allow surgeons to perform operations on soldiers from a distance have increased the demand for telerobotic surgeries. Nowadays it is reality, with more than one surgical procedures described; the current robotic platforms enable remote access, without the need for the surgeon to be present physically in the operating theatre.

Furthermore, the use of tablets and smartphones to talk with patients, colleagues and hospitals will be the new way of communication.

The introduction of virtual reality simulation in the 1990s paved the way for surgical simulation. At the beginning of the century, simulators have been introduced for laparoscopic surgery and they are currently at our disposal for robotic training too. Simulators allow trainees to acquire surgical skills in a safe and controlled environment.

On the whole, surgical procedures, instruments, operating rooms, way of communication, training courses, all has changed in the recent years.

We have reached the 'technological and smart surgery era' and 'mobile healthcare'.

Keywords: BPH, LUTS, Surgery, Technological era

Anahtar Kelimeleri: BPH, LUTS, Cerrahi, Teknolojik dönem
Informed Consent: Unnecessary.

Peer-review: Internally peer-reviewed

Financial Disclosure: The author declared that this study received no financial support.

\section{References}

1. Rassweiler J, Teber D, Kuntz R, Hofmann R. Complications of transurethral resection of the prostate (TURP)--incidence, management, and prevention. EurUrol 2006;50:969-979.

2. 2.Gilling PJ, Cass $C B$, Malcolm $A R$, Fraundorfer MR. Combination holmium and Nd:YAG laser ablation of the prostate: initial clinical experience. J Endourol 1995;9:151-153.

3. Mariano MB, Graziottin TM, Tefilli MV. Laparoscopic prostatectomy with vascular control for benign prostatic hyperplasia. J Urol 2002;167:25282529.

4. Desai MM, Aron M, Berger A, Canes D, Stein R, Haber GP, Kamoi K, Crouzet S, Sotelo R, Gill IS. Transvesical robotic radical prostatectomy. BJU Int 2008;102:1666-1669.

5. 5.Namdarian B, Dasgupta P. What robot for tomorrow and what improvement can we expect? Curr Opin Urol 2018;28:143-152.

6. 6.Bhatt NR, Davis NF, Dalton DM, McDermott T, Flynn RJ, Thomas AZ, Manecksha RP. Quantitative Analysis of Technological Innovation in Urology. Urology 2018;111:230-237. 